\title{
12 Progress and challenges with comprehensive sexuality education
}

\author{
What does this mean for HIV \\ prevention in the ESA region?
}

\author{
Patricia Machawira, Chris Castle and \\ Joanna Herat
}

\section{Introduction}

The Eastern and Southern Africa (ESA) region has 158 million young people aged $10-24$, accounting for nearly $30 \%$ of the global population. This number is expected to rise to 281 million by 2050 (UNESCO, UNFPA and UNAIDS, 2016; AFIDEP and UNFPA, 2015). Unfortunately, a majority of these young people are facing significant sexual and reproductive health challenges. According to UNAIDS estimates (2016), less than 50\% of young people demonstrate accurate knowledge about HIV prevention and transmission. Many studies emphasize that young adolescent girls in the region have very little knowledge about their sexual and reproductive health, in part due to social and cultural taboos against informing girls (and boys) about the changes to their bodies and relations as they mature. They are particularly at risk, not only for HIV but also early and unintended pregnancies (EUP), sexually transmitted infections (STIs), gender-based violence (GBV) and child marriage. Further research has shown that adolescent girls (15-19 years) in the sub-Saharan African region experience the highest rates of pregnancy in the world (UNFPA, 2013), often unintended, and largely because sex, marriage and pregnancy are often not consensual for them due to persisting gender-discriminatory norms and limited knowledge related to their sexuality.

Ensuring access to information and education on sexual health, power relations and gender norms is an essential component to address those issues. The shift from traditional forms of communication and learning within the extended family to a reliance on a mixture of family, school, peers and media has left an apparent gap in education that is relevant to young people in today's world in this region. The fear-based HIV prevention messages of the 1990s and 2000s have been shown to have little or no impact on the way that young people navigate their transition to adulthood, including their relationships. And in line with shifts in educational 
philosophy worldwide that prioritize the building of skills and critical thinking, education about health and HIV has undergone significant rethinking.

Comprehensive sexuality education (CSE) is the result of this process and empowers young people to make informed decisions about relationships and sexuality. Well-delivered CSE provides education about human rights, gender equality, relationships, reproduction, sexual behaviours, risks and prevention of ill health.

The newly revised UN International Technical Guidance on Sexuality Education defines CSE as a curriculum-based process of teaching and learning about the cognitive, emotional, physical and social aspects of sexuality (UNESCO, 2018a). It aims to equip children and young people with the knowledge, skills, attitudes and values that will empower them to realize their health, well-being and dignity; develop respectful social and sexual relationships; consider the well-being of others who are affected by their choices; and understand and ensure the protection of their rights throughout their lives. This definition of CSE stems from a human rights and empowerment-based approach essential to address sexual and reproductive health issues as well as gender inequality in ESA. It reflects development in the field, for example by integrating key structural issues of gender and power, which tend to be avoided in other definitions in the literature (Haberland, 2015).

Given the need for young people to realize their health in sexual relationships, this chapter will provide an overview on the evolution of sexuality education in the ESA region and assess the effectiveness of the CSE programmes on behavioural and biological indicators, notably with regards to HIV prevention, and their potential to bring broader social change. The chapter will end with the challenges raised by the scale-up of these programmes and a summary of the lessons learnt from implementing CSE programmes in ESA region.

\section{History of CSE in the ESA region}

\section{From LSE to CSE}

Since the early 1990s, ESA countries have been implementing life skills education (LSE) programmes supported by development partners, mostly as a response to HIV. The programmes did not have a common definition of life skills but rather included a range of generic personal, interpersonal, cognitive and psychosocial skills and knowledge. Similarly, the content, level of application and terminology used varied from country to country according to priorities and context.

The 2012 Global Evaluation of LSE Programmes found that in general LSE was relevant to national priorities and the lives of learners (UNICEF, 2012). However, while coverage was growing through integration into school curricula, implementation was a challenge. LSE was often squeezed 
out because of teacher shortages, overcrowded curricula, limited teaching material and the focus on traditional examinations. In addition, there were few opportunities for meaningful and systematic participation of learners' voices in designing interventions that take into account varying contexts, needs and interests. Most importantly, life skills prevention education was often sub-optimal because it failed to explore intersections between gender, sex and social relationships. Further, the content and delivery of LSE was restricted in its capacity to move beyond knowledge and into the development of psychosocial skills, attitudes and behaviours. The result is that many young people grow into adolescence and adulthood without the basic capabilities needed to access and utilize SRH services in an appropriate way.

Following the insights into the shortcomings of the LSE programmes, there was general realization that in their current form, the programmes had failed to equip young people with the adequate life skills (and at times basic knowledge) to enable appropriate decisions on sexual health and encourage more positive sexual behaviours. The weaknesses inherent in the current approach shifted the momentum towards a closer analysis of the role of sexuality education in promoting the well-being of adolescents with later agreements affirming the interrelations between sexual and reproductive health, gender equality and human rights (Haberland, 2015). Notably, the 1994 International Conference on Population and Development is seen as a key signpost for the introduction of this shift towards sexuality education and CSE.

This was strengthened by the 2009 introduction of the UN International Technical Guidance on Sexuality Education. For most countries, this document instigated a second generation of CSE programmes which often built on existing programmes and content. Some CSE topics are present in most school curriculums and there is a large overlap between CSE and LSE, dependent on each country context and the thematic areas of its LSE programme. Thus, the current programmes evolved from the strengthening of already existing LSE programmes through the enhancement of CSE content.

One of the major challenges has been to define sexuality education, particularly because the key elements stemmed from the different terminologies used across national policies and curricula. While CSE is the globally recognized term, in ESA and elsewhere the terminology varies. It is also known as prevention education, relationships and sexuality education, SRH education, population and family life education, life skills education, healthy lifestyles and the basics of life safety and so on. The differences of terminology have been accompanied with varying approaches, leading sometimes to a weakening of the CSE's contribution to the human rightsbased agenda and the empowerment basis it is grounded on (UNESCO, 2017).

An internationally recognized guidance based on research and best practices to guide both essential content and methodology has been 
co-developed by UNESCO and other UN partners to serve as an educational resource, assisting decision-makers and programme designers in the conception of CSE curriculum. Many programmes in this region have used this guidance to inform the revision of their national curricula, and the publication of the revised edition in early 2018 offers an opportunity to review and strengthen these programmes. The revised International Technical Guidance on Sexuality Education recommends concepts and learning objectives that are logically staged, starting with developmentally appropriate concepts for younger children and building up to more complex concepts, information and activities for older children (UNESCO, 2018a). This ensures that when properly sequenced, CSE is in line with the age and cognitive abilities of learners with the following key eight concepts which are further delineated into three domains of learning knowledge, attitudes and skills:

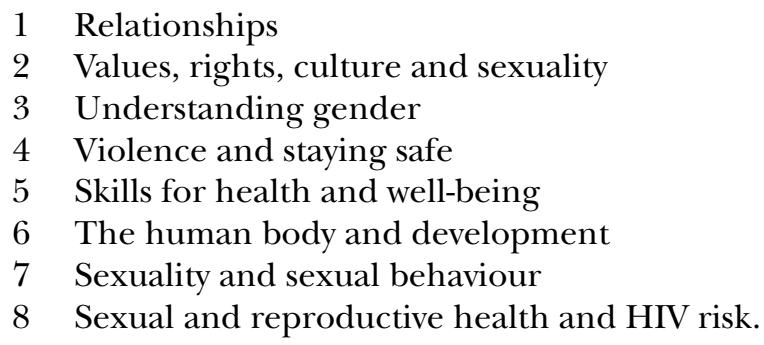

Each concept presents the opportunity to address different topics; for example, 'relationships' includes the topics of families, friendship, love and romantic relationships, tolerance and respect, long-term commitment to marriage, and parenting. Given that the SRH needs of young people vary among countries - and even communities - and that countries are governed by different laws and policies, topics and learning objectives should be adjusted to the context in which they are provided and based on available local, national and international evidence.

\section{The ESA Ministerial Commitment: a tipping point for CSE}

The endorsement of the ESA Ministerial Commitment by the region's leadership on 7 December 2013 has ushered in a strong movement in support of CSE. The ESA Commitment meant that the political will to ensure access to CSE has been affirmed at the highest decision-making level, explicitly prioritizing 'ensuring access to good quality, comprehensive, life skillsbased HIV and sexuality education and youth-friendly sexual and reproductive health services for all adolescents and young people' (UNESCO, 2013). The ESA Commitment put the spotlight on young people and promoted inter-sectoral collaboration while rallying partners around four key results 
for adolescents and young people: reducing HIV infection, reducing early and unintended pregnancy, reducing gender-based violence and eliminating child marriage.

Seven years after its endorsement, the ESA Commitment is seen as a key driver with regards to scaling up CSE. The political momentum provided by the ESA commitment has led many governments to scale up delivery of CSE within the formal school curriculum, such that by the end of 2015,14 out of 20 ESA countries reported providing CSE in $40 \%$ of schools, and all 20 countries declared having in-service teacher training programmes on CSE (UNESCO, UNFPA and UNAIDS, 2016).

Positive impacts of the ESA Commitment include providing a policy framework with set short- and long-term targets to facilitate the scale-up of CSE and helping to fast-track the process of strengthening CSE in existing policies, strategies and programs. It has also facilitated the strengthening of the collaboration between the Ministry of Education and Ministry of Health in the planning and delivery of CSE, improving collaboration between governmental and non-governmental stakeholders and mobilizing donors around a common agenda. The requirements for countries to periodically report on progress on the ESA Commitment targets, thus subjecting them to peer evaluation, has added impetus and consistency to the implementation of CSE. Similarly, the inclusion of CSE in other regional policy and technical guidance documents has provided a framework for country investments.

Most ESA countries are now embracing the concept of CSE and are engaged in strengthening its implementation at national level. In this regard, more attention has been given to review of national curricula to integrate CSE and scale-up of effective teacher training and investment in monitoring systems together with engagement of parents and communities. In concert with national governments and civil society, development partners (including the UNAIDS Joint Programme) are supporting countries in their efforts to develop curricula that reflects the country context and that will have a direct, beneficial impact on the HIV response and more widely on adolescent and young people's health.

While ESA has seen an increase in the provision of CSE in the curriculum, issues of quality become important. In 2015, UNESCO commissioned a fivecountry study to assess the quality of CSE curricula and delivery (Uganda, Zambia, Lesotho, Malawi, Namibia). The review used an in-depth assessment tool, the Sexuality Education Review and Assessment Tool (SERAT), completed with key stakeholders. SERAT results (see Figure 12.1) across all five countries revealed moderate to strong curriculum content for the 9-18 age range, and weak to no content for the 5-8 age range, with the exception of Malawi. In Lesotho, Uganda and Zambia, CSE is offered from age 10 onwards, and there is no CSE curriculum developed for the younger age group (5-8 years). 


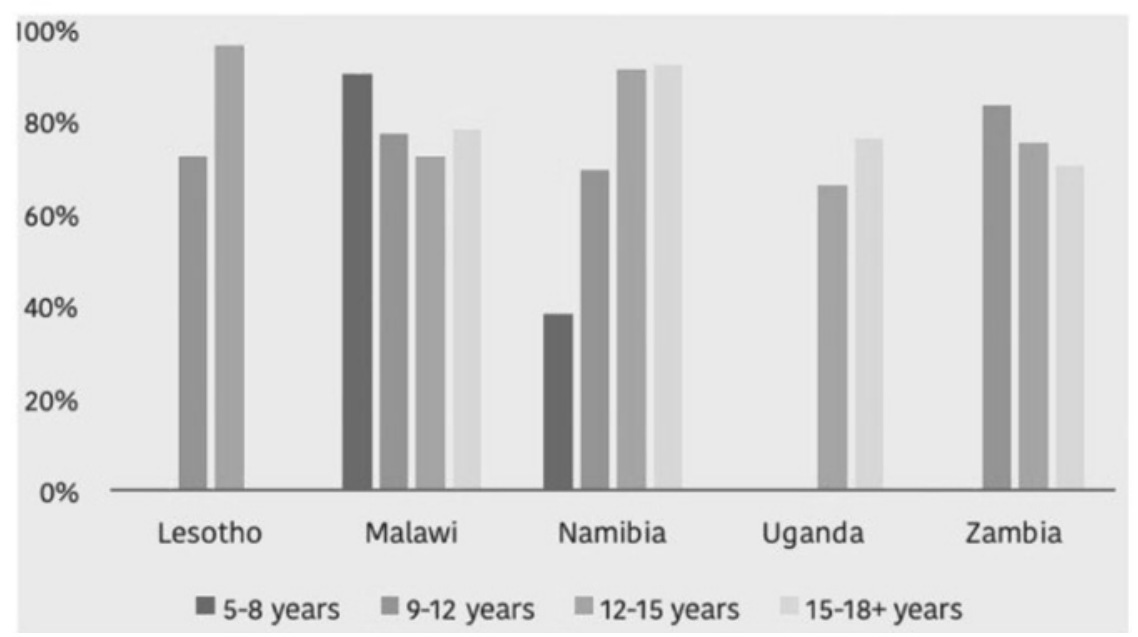

Figure 12.1 Average score of comprehensiveness of content in the CSE curriculum by age group

\section{Analysis of effectiveness}

\section{CSE: an effective approach?}

Whilst the rationale for delivering CSE to children and young people is partly situated within a rights-based framework, recognizing the right to a quality education and the right to information and education about $\mathrm{SRH}$, the need for clear evidence on the effectiveness of CSE is nonetheless critical. Through two major reviews of evidence commissioned by UNESCO and conducted by independent experts, it is possible to understand the impact of sexuality education on some health-related outcomes (sexual behaviour, unintended pregnancy) as well as outcomes such as knowledge and attitudes, which are a pre-condition for healthy behaviours. These two reviews have considered the results of more than 150 studies from countries in the global north and the global south, including in sub-Saharan Africa (UNESCO, 2009, 2018c). The authors sought systematic reviews that included school-based CSE programmes $(N=77)$. Many of the reviews also included non-school-based programmes (in clinics or communities), and in some cases they performed direct comparisons between school-based and non-school-based programmes. The authors also sought systematic reviews that included at least some RCTs but often also included non-RCTs, case-control studies, before-after studies and cross-sectional surveys $(N=65)$. 
Based on this evidence, curriculum-based sexuality education programmes are likely to contribute to the following outcomes:

- Delayed initiation of sexual intercourse (Guse et al., 2012)

- Decreased frequency of sexual intercourse

- Decreased unintended pregnancy

- Decreased number of sexual partners

- $\quad$ Reduced STIs

- $\quad$ Reduced risk-taking: increased use of condoms (Fonner et al., 2014) and increased use of contraception.

The evidence reviewed in 2018 also demonstrates that sexuality education leads to increased knowledge about different aspects of sexuality and behaviours, including risks of pregnancy and HIV and other STIs (Guse et al., 2012). Sexuality education is also strongly correlated with improved attitudes related to sexual and reproductive health, as shown for instance in a systematic review of the school programmes in Nigeria (Amaugo et al., 2014).

More generally, the evidence from sub-Saharan Africa has shown that the implementation of sexuality education has led to significant improvements in HIV-related knowledge and to delayed sexual debut (Ross et al., 2007). In Kenya, there was a significant positive difference in condom use between the intervention and control groups in the follow-up of a national primary school HIV intervention (Maticka-Tyndale, Wildish and Gichuru, 2010). Combining education with the provision of health services has shown positive effects on unintended pregnancy rates (Mavedzenge et al., 2011; Hindin et al., 2016) and/or delayed sexual debut. This approach highlights the importance of adopting an intersectoral efforts and recognizing that the mobilization of community and the provision of youth-friendly services alongside any school-based programme may be key drivers of its success.

In addition, CSE programmes have shown in some instances to be more effective than programmes only aiming at delaying sexual initiation after marriage on moral and/or public health grounds (Boonstra, 2011). Many studies assessing 'abstinence-only' programmes showed that this approach fails to increase the use of condoms, to avoid risk-taking attitudes or even to delay the date of sexual debut (Trenholm et al., 2007; Underhill, Operario and Montgomery, 2007). Besides, abstinence-only policies have the potential to be harmful for young people by depriving them of the basic information they need on HIV and sexuality - a critical issue in sub-Saharan Africa, where most young people have sex before the age of 18 (Amo-Adjei and Tuoyire, 2018).

\section{The scope for improvement of CSE programmes}

Despite the positive results of the implementation of CSE in the ESA region and worldwide, these conclusions must be nuanced. First, the outcomes 
observed on CSE are usually only slightly positive, and the quality and fidelity of the implementation play major roles here. Moreover, a third of the CSE programmes still have limited effect on the attitudes and behaviours of the targeted learners. Another challenge resides in the fact that it is still not possible to draw direct causal pathways between the delivery of sexuality education and biological outcomes such as reduced HIV/STIs or EUP. This is partly a result of the limited number of high-quality longitudinal trials and partly because of the range of confounding factors which are critical to HIV prevention efforts, such as the availability of services (including condoms), and the wider structural and behavioural factors which reduce agency or increase vulnerability. Hence, most of the studies only measure behavioural changes because this is easier and less costly, even if biological indicators are the better way to assess the effectiveness of CSE programmes.

CSE is a privileged means to create a shift in young people's minds to reach gender equality and enable them to empower themselves (Boonstra, 2011). Indeed, CSE programmes grounded on an empowerment-based approach, thus highlighting gender and power in their curricula, have shown noteworthy results. For instance, a three-year study conducted in junior secondary high schools in the Lagos State of Nigeria assessed the impact of the 'Family Life and HIV Education' curriculum delivered to young people. The curriculum covered subjects such as human sexual development and sexual health, skills for negotiating personal and intimate relationships, and gender-equitable attitudes. At the end of the study, young people presented greater knowledge of SRH, expression of gender-equitable attitudes, confidence about saying no to pressures to have sex and (among boys) a commitment not to pressure girls to engage in sex (Action Health Incorporated, 2010). Other studies in Nigeria and elsewhere showed how gender-sensitive programmes lead to the development of gender-equal and peaceful relationships (Madunagu, 2003; Verma et al., 2008).

Furthermore, there is increasing evidence that emphasizing gender and power in CSE programmes is more efficient in impacting positively on attitudinal and biological outcomes (i.e. decreasing rates of STDs and EUP). For instance, in recent literature, gender is referred to as 'a gateway to SRH outcomes' (Haberland, 2010; Middlestadt et al., 2012). Unfortunately, CSE and LSE programmes in the ESA region are still not emphasizing these issues enough, and a review of the literature on gender and CSE in South Africa has also shown that Life Orientation programmes can even reinforce gendered power relations because of persistent punitive, paternalistic approaches to young people's sexuality, among many other reasons (Shefer and Macleod, 2015).

CSE has the potential to be a catalyst for social change and to enhance non-violent relationships, based on respect between young people and control over their own lives and bodies. The Stepping Stones life skills programmes in South Africa and The Gambia are striking examples of effective 
sexuality education. In the two-year period after the intervention, boys and men shifted attitudes and were less engaged in violent behaviours: fewer were involved in incidents of intimate partner violence (Dunkle et al., 2006), rape (Jewkes et al., 2006) and transactional sex (Dunkle et al., 2007).

\section{Strategies for scale-up}

\section{Scale-up of CSE in the ESA region}

In view of the challenges and HIV and SRH-related issues faced by youth in the ESA region, it is critical that countries pursue efforts in the light of the ESA commitment to scale-up CSE. In 2016, only 10 in 21 countries of the region had coordination mechanisms, work plans and mobilized resources for implementation (UNESCO, UNFPA and UNAIDS, 2016).

UNESCO identifies the three following aspects to ensure an effective scale-up, notably based on evidence and successful strategies (Fonner et al., 2014; Haberland and Rogow, 2015):

- $\quad$ The creation of an enabling environment for the implementation of CSE programmes, with a conducive legal and policy environment, a strong leadership and a costed scale-up plan.

- Decisions on the different technical considerations that will affect the scale-up, such as the development and contents of a CSE curriculum framework, the choice of the CSE delivery model to use, the form of training that will be provided to the teachers and an effective M\&E system.

- Addressing factors that affect the delivery of CSE through creating a conducive and safe physical and psychosocial environment in schools and communities with effective parental engagement and linkages to SRH services and out-of-school delivery.

The International Technical Guidance on Sexuality Education (UNESCO, 2018a) gives the following characteristics of effective CSE programs based on a review of various CSE programs from across the world:

\section{Preparatory phase}

1 Involve experts on human sexuality, behaviour change and related pedagogical theory.

2 Involve young people, parents/family members and other community stakeholders.

3 Assess the social SRH needs and behaviours of children and young people targeted by the programme, based on their evolving capacities.

4 Assess the resources (human, time and financial) available to develop and implement the curricula. 


\section{Content development}

5 Focus on clear goals, outcomes and key learnings to determine the content, approach and activities.

6 Cover topics in a logical sequence.

7 Design activities that are context-oriented and promote critical thinking.

8 Address consent and life skills.

9 Provide scientifically accurate information about HIV and AIDS and other STIs, pregnancy prevention, early and unintended pregnancy and the effectiveness and availability of different methods of protection.

10 Address how biological experiences, gender and cultural norms affect the way children and young people experience and navigate their sexuality and their SRH in general.

11 Address specific risk and protective factors that affect particular sexual behaviours.

12 Address how to manage specific situations that might lead to HIV infection, other STIs, unwanted or unprotected sexual intercourse or violence.

13 Address individual attitudes and peer norms concerning condoms and the full range of contraceptives.

14 Provide information about what services are available to address the health needs of children and young people, especially their SRH needs.

\section{Challenges for scaling up CSE in the ESA region}

In understanding the gap between existing data on HIV knowledge levels and the persistently high rates of new HIV infections, it is necessary to examine in depth the quality of education as well as the domestic structures within which sexuality education is being housed. Many countries in the region face systemic challenges in delivering a quality education to all learners, including maths, literacy, science and other traditionally 'core' subjects. Sexuality education is subject to the same stresses as these other subjects: a high ratio of learners to teachers, weak programmes for teacher training and support, very limited teaching and learning resources and a persistence of traditional pedagogical approaches that prioritize a 'chalk and talk' approach over the active participation of learners (UNESCO, 2012; UNFPA, 2012). Hence, young people lack the favourable environment to cultivate critical thinking and the necessary skills to empower themselves and become confident citizens. This environment is however vital to achieve gender equality (Pettersson, 2014).

Teachers are at the core of catalytic actions in the scale-up of CSE. Governments and stakeholders need to emphasize the importance of the continuous training of teachers and to provide the adequate means to enable them to adapt to the requirements of teaching CSE. This includes the capacity to 
provide an interactive pedagogy, the confidence to talk about sexuality and the ability to create a healthy and respectful environment in the classroom. Then, major investments are needed in the provision of quality and sufficient teaching and learning materials for all schools.

The ESA region has seen relative success with reaching young people in the school system. However, achieving universal access to good-quality CSE will require specific strategies for reaching marginalized young people who are out of school. Evidence shows that the vulnerability of youth increases when they exit school upon completion or due to dropout (World Bank, 2015). In many countries, the dropout rate is especially high between primary and secondary levels, which is also often just at time of, or just after, sexual initiation (UNESCO, 2012). This means that even if CSE is scaled up nationally through formal education, a large number of young people will not access it (World Bank, 2015). For those who are in school, informal and non-formal sexuality education is important to reinforce and even go further than what is provided in the classroom. Thus, there is a need for an out-of-school CSE delivery strategy that uses the CSE curriculum or similar content used in schools to ensure continuity from school to out-ofschool CSE provision (UNESCO, 2018b). This will be an important next step to reach young people living with disabilities or with HIV, those living in extreme poverty, those with higher HIV risk or teenage mothers. In the case of the latter, despite policies to the contrary, many schools in countries in the ESA region still adopt a punitive approach and exclude young mothers from school as soon as they get pregnant (UNESCO, UNFPA and UNAIDS, 2016).

Finally, cultural and religious conservatism often weakens expansion of CSE, and a major challenge resides in the overcoming of these resistances. In general, public discussions around sex and sexuality are highly sensitive, and parents as well as community leaders still fear that talking about sexuality will lead to earlier sexual debut or an increased number of sexual partners among young people (Barboza, 1993). The case of Nigeria is a remarkable example of how to address these issues through effective action. Stakeholders were reluctant to implement CSE, and policy-makers created early advisory and advocacy committees to facilitate the dialogue with and to inform key CSE stakeholders: community and religious leaders, school administrators and representatives of teacher unions and parents associations. Moreover, the model was adaptive to social and cultural characteristics of different federal states, and strategic changes of names of curriculum were made. For example, in the Sokoto State the name of the curriculum was changed from 'Family Life and HIV/AIDS Education' to 'School Health Education Program'. The scale-up had relative success, despite compromises and the fact that Islamic schools are still less likely to provide CSE than Christian schools (Huaynoca et al., 2013).

To deal with opposition, countries need to build community support by strategically choosing the issues to address, framing their work with care, 
having sensitive content vetted and actively reaching out to all stakeholders to explain what they were doing. A second key element is to deal with backlash by using supportive media persons as intermediaries, arranging for journalists to visit the schools and see for themselves what was going on, and organizing information-sharing discussion sessions.

\section{Lessons learnt from implementing CSE programmes in the ESA region}

1 Nationwide coverage of CSE is impossible without government leadership and ownership. For CSE expansion to be effective and sustainable, it must be integrated into existing systems and become part of the core business of a ministry of education. As such, this requires changes to policy, laws and budgets, which is impossible without high-level commitment and leadership. High-level leadership and ownership contribute to changing the environment in which CSE is offered and provide a mandate and justification to teachers and other implementers to provide CSE. They can also contribute to making the provision of CSE (and HIV-SRH services) acceptable to gatekeepers.

2 If CSE is to be effectively expanded, it requires integration of M\&E into existing ministry systems. At the national level, tools such as the Annual School Census (ASC) and analysis by the Education Management Information System (EMIS) should include CSE components and, therefore, data collection forms and $\mathrm{M} \& \mathrm{E}$ training may need to be amended to reflect these additions. Such indicators, if introduced via the EMIS, can help countries track CSE delivery and enable policy and programmes to be adapted as needed.

3 To ensure full support for CSE, there is need to engage with key gatekeepers, at the state and community level, to garner their support in the creation of a conducive environment for CSE. Parents can play an important role in communicating with their children about sexuality, relationships and well-being. Studies have repeatedly shown that favourable parental attitudes influence children's attitudes. Parents and families play a key role in shaping attitudes, norms and values related to gender roles, sexuality and the status of adolescents and young people in the community (Svanemyr et al., 2015).

4 The respect of human rights needs to be a priority for countries which provide CSE to ensure an equal and safe access for all. This means, for instance, that countries should foreclose any punitive, criminalizing laws or policies regarding sexual orientation, consensual sex among minors or teenage pregnancy, and any other policy that would violate the basic human rights essential to CSE successful delivery.

5 Despite all countries in ESA now heading towards implementation of CSE, a number of ongoing challenges remain with some of the CSE curricula. The lack of appropriate attention to gender norms and roles 
as well as power relations in CSE curricula represents a stark disconnect from the reality for most adolescent girls and young women. In addition, curricula are often missing essential content, especially around pregnancy prevention and gender.

6 Teacher training remains a weak point in most sexuality education programmes. Developing and updating training curricula and supporting teachers to examine their own values and biases remains a priority. The quality of CSE delivered to young people depends ultimately upon teachers' knowledge, confidence and skill to deliver the subject. Teachers must be adequately trained in the subject matter and in more participatory pedagogical approaches. Teachers frequently focused on knowledge rather than skills and used didactic methods rather than engaging pupils through participatory approaches. Increasingly, teacher-training programmes in the region are now focusing on examining personal attitudes and values to improve comfort and confidence as well as the content and teaching skills required.

7 While the ESA Commitment has increased inter-sectoral collaboration, more must be done to ensure that adolescents and young people receiving CSE have access to youth-friendly health services. Having the knowledge, attitudes and skills to make healthy decisions is insufficient without access to services and commodities. Too often, young people access services when it is too late, in part because of fear, discomfort, embarrassment and gatekeeper disapproval. The education sector has a role to play in improving linkages between schools and healthcare facilities, including through providing referrals.

\section{Conclusion}

Comprehensive sexuality education, if well implemented, has the potential to address many issues related to HIV and SHR faced by young people in the ESA region. ESA commitment has been a great boost to the CSE agenda in the ESA region and it can become a foundation for ensuring political engagement in different public health issues. Many ESA countries have embraced the concept of CSE and are supporting its implementation, which is vital to reduction of HIV rates in the region. However, most country policies and sociocultural environments are still not sufficiently capacitated to reach these goals, and the path will be long before a comprehensive, empowerment-based sexuality education can be provided to all young people in and out of school. Emphasizing gender is pivotal to this achievement, as evidence has shown, and further investigation needs to be undertaken to assess the interrelations between CSE, gender equality and human rights and their impact on the health and well-being of young people.

To achieve effective and widespread delivery, advocacy and informationbuilding on CSE must be continuous, and the furthering of the scientific literature on CSE plays a major role here, as it is the base of any plausible 


\section{Patricia Machawira et al.}

advocacy. Future research is required to answer some unexplored questions, such as the factors affecting the successful transfer of knowledge and values within the classroom and why stubborn gaps remain between teachers' generally high knowledge levels on HIV/AIDS and low levels of student knowledge on HIV.

Another key area for assessment are the specific components to prioritize for ensuring effective CSE delivery, acknowledging that a comprehensive curriculum review is not always due to a lack of time and resources. Lastly, more inquiry is needed on how to reach the most vulnerable young people, especially marginalized young people outside of educational settings, and to ensure the quality and relevance of sexuality education to their lives and needs. 


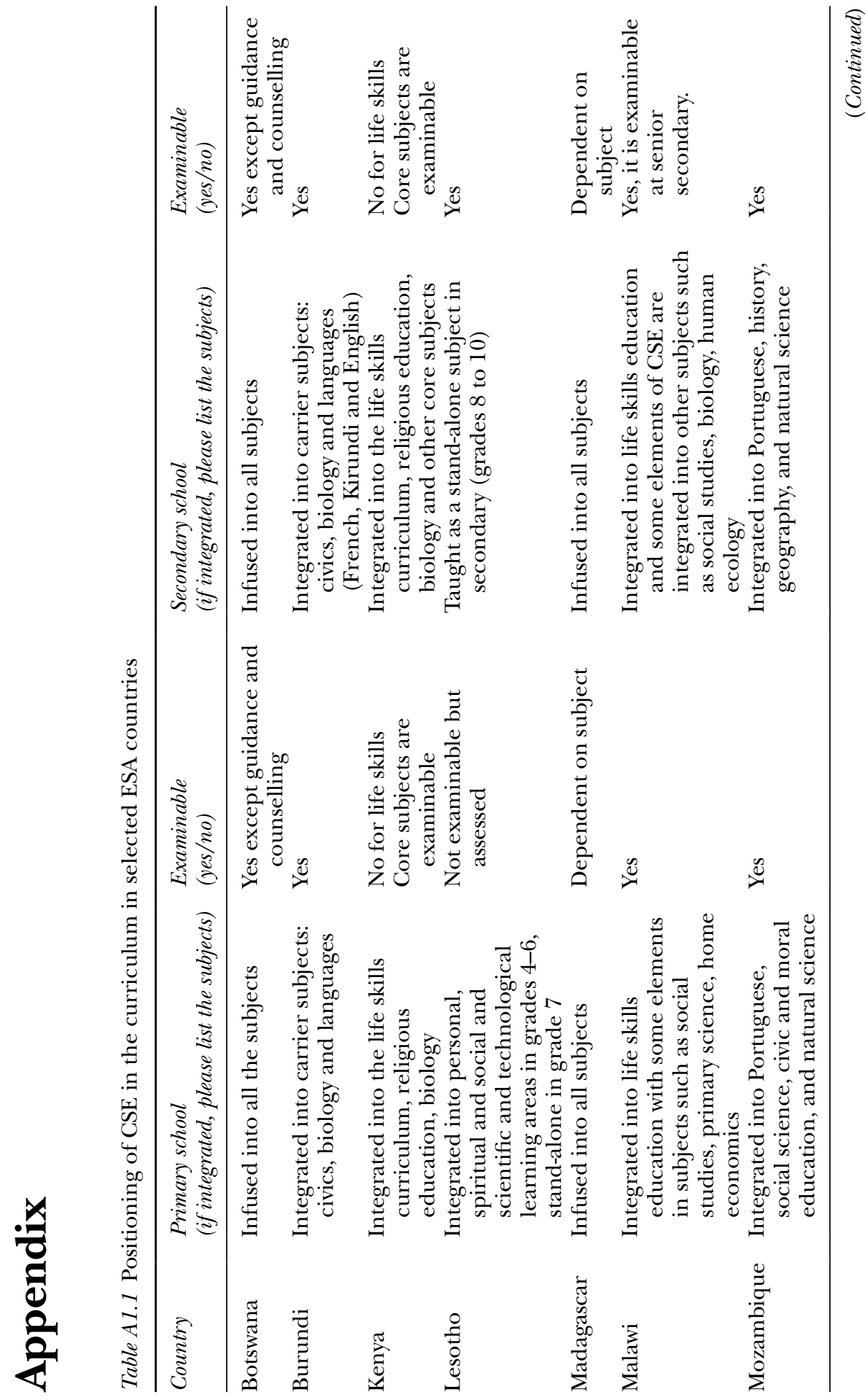




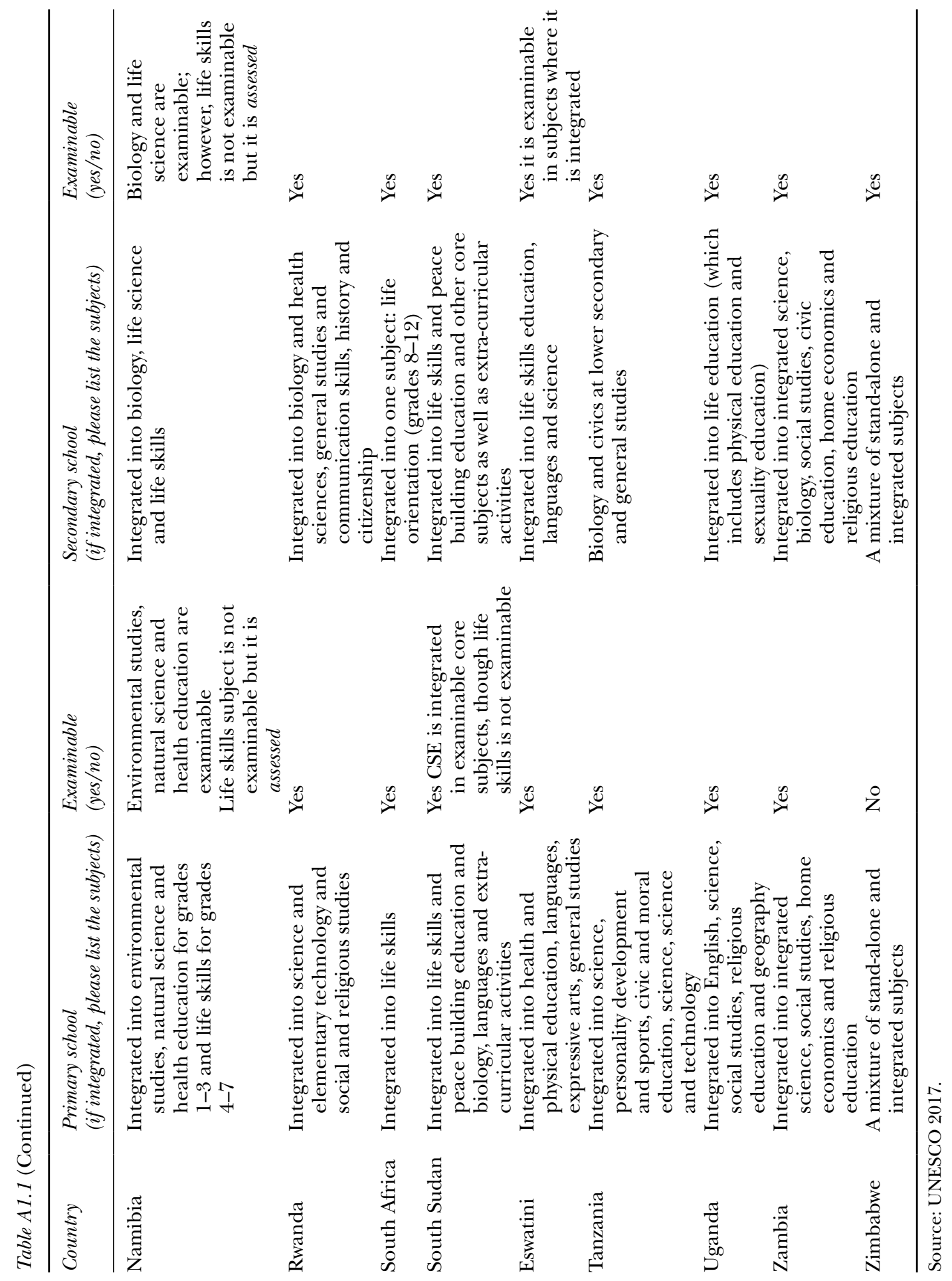




\section{References}

Action Health Incorporated. 2010. Foundation for a healthy adulthood: Lessons from school-based family life and HIV education curriculum implementation in Lagos state. Lagos: Action Health Incorporated and Lagos State Ministry of Education.

AFIDEP and UNFPA. 2015. Synthesis report on the demographic dividend in Africa. Johannesburg: UNFPA East and Southern Africa Regional Office.

Amaugo, L. G., Papadopoulos, C., Ochieng, B. M. and Ali, N. 2014. The effectiveness of HIV/AIDS school-based sexual health education programmes in Nigeria: A systematic review. Health Education Research, 29(4), pp. 633-648. https://doi. org/10.1093/her/cyu002

Amo-Adjei, J. and Tuoyire, D. 2018. Timing of sexual debut among unmarried youth aged 15-24 years in sub-Saharan Africa. Journal of Biosocial Science, 50(2), pp. 161-177. doi:10.1017/S0021932017000098.

Barboza, Nathalie. 1993. Breda series no. 2: Développement des programme et projets d'éducation en matière de population en Afrique francophone et lusophone [Breda series \#2: The development of population education programmes and projects in francophone and Portuguese-speaking Africa]. Dakar: UNESCO.

Boonstra, H.D. 2011. Advancing sexuality education in developing countries: Evidence and implications. Guttmacher Policy Review, 14(3).

Dunkle, K. L., Jewkes, R. K., Nduna, M., Jama, N., Levin, J., Sikweyiya, Y. and Koss, M.P. 2007. Transactional sex with casual and main partners among young South African men in the rural Eastern Cape: Prevalence, predictors, and associations with gender-based violence. Social Science E् Medicine, 65, pp. 1235-1248. https:/ / doi:10.1016/j.socscimed.2007.04.029.

Dunkle, K.L., Jewkes, R.K., Nduna, M., Levin, J., Jama, N., Khuzwayo, N., Koss, M.P. and Duvvury, N. 2006. Perpetration of partner violence and HIV risk behaviour among young men in the rural Eastern Cape, South Africa. AIDS, 20(16), pp. 2107-2114.

Fonner, V.A., Armstrong, K.S., Kennedy, C.E., O'Reilly, K.R. and Sweat, M.D. 2014. School based sex education and HIV prevention in low-and middle-income countries: A systematic review and meta-analysis. PLoS One, 9(3), p.e89692. doi:10.1371/journal.pone.0089692.

Guse, K., Levine, D., Martins, S., Lira, A., Gaarde, J., Westmorland, W. and Gilliam, M. 2012. Interventions using new digital media to improve adolescent sexual health: A systematic review. Journal of Adolescent Health, 51 (6), pp. 535-543.

Haberland, N.A. 2010. What happens when programs emphasize gender? A review of the evaluation research. Presented at UNFPA global technical consultation on comprehensive sexuality education, Bogota, Colombia, November 30.

Haberland, N.A. 2015. The case for addressing gender and power in sexuality and HIV education: A comprehensive review of evaluation studies. International Perspectives on Sexual and Reproductive Health, 41(1), pp. 31-42.

Haberland, N.A. and Rogow, D. 2015. Sexuality education: Emerging trends in evidence and practice. Journal of Adolescent Health, 56(1), pp. S15-S21. https://doi. org/10.1016/j.jadohealth.2014.08.013

Huaynoca, S., Chandra-Mouli, V., Yaqub, N. and Denno, D. M. 2014. Scaling up comprehensive sexuality education in Nigeria: From national policy to nationwide application. Sex Education, 14(2), pp. 191-209. doi:10.1080/14681811.201 3.856292 . 
Hindin, M.J., Kalamar, A.M., Thompson, T.A. and Upadhyay, U.D. 2016. Interventions to prevent unintended and repeat pregnancy among young people in low-and middle-income countries: A systematic review of the published and gray literature. Journal of Adolescent Health, 59(3), pp. S8-S15.

Jewkes, R., Dunkle, K., Koss, M.P., Levin, J. B., Nduna, M., Jama, N. and Sikweyiya, Y. 2006. Rape perpetration by young, rural South African men: Prevalence, patterns and risk factors. Social Science $\mathcal{E}$ Medicine, 63(11), pp. 2949-2961.

Madunagu, B., ed. 2003. Training manual level 1: Adolescent sexuality, sexual and reproductive health and rights. Calabar: Girls Power Initiative.

Maticka-Tyndale, E., Wildish, J. and Gichuru, M. 2010. Thirty-month quasiexperimental evaluation follow-up of a national primary school HIV intervention in Kenya. Sex Education, 10(2), pp. 113-130.

Mavedzenge, S. M. N., Doyle, A.M. and Ross, D.A. 2011. HIV prevention in young people in sub-Saharan Africa: A systematic review. Journal of Adolescent Health, 49(6), pp. 568-586.

Middlestadt, S. E., Pulerwitz, J., Acharya, K. et al. 2012. Evidence for gender as a gateway factor to other behaviors: Ethiopia. The Health Community Partnership's End of Project Meeting. www.jhuccp.org/legacy/pubs/HCP_endofproject/3Acharya. ppt. Accessed December 3, 2012.

Pettersson, T. 2014. Basic values and civic education: A comparative analysis of adolescent orientations towards gender equality and good citizenship. www.worldvaluessurvey.org/ library/. Accessed August 11, 2014.

Ross, D. A., Changalucha, J., Obasi, A. I., Todd, J., Plummer, M. L., Cleophas-Mazige, B., Anemona, A., Everett, D., Weiss, H.A., Mabey, D. C. and Grosskurth, H. 2007. Biological and behavioural impact of an adolescent sexual health intervention in Tanzania: A community-randomized trial. AIDS, 21(14), pp. 1943-1955.

Shefer, T. and Macleod, C. 2015. Life orientation sexuality education in South Africa: Gendered norms, justice and transformation. Perspectives in Education, 33(2), pp. 1-10.

Svanemyr, J., Amin, A., Robles, O.J. and Greene, M.E. 2015. Creating an enabling environment for adolescent sexual and reproductive health: A framework and promising approaches. Journal of Adolescent Health, 56(1), pp. S7-S14.

Trenholm, Christopher, Devaney, Barbara, Fortson, Ken, Quay, Lisa, Wheeler, Justin and Clark, Melissa. 2007. Impacts of four title V, section 510 abstinence education programs. MATHEMATICA Policy Research. https://www.mathematica. org/our-publications-and-findings/publications/impacts-of-four-title-v-section510-abstinence-education-programs.

UNAIDS and the African Union. 2015. Empower young women and adolescent girls: Fast tracking the end of the AIDS epidemic in Africa. Geneva: UNAIDS.

Underhill, K., Operario, D. and Montgomery, P. 2007. Systematic review of abstinence-plus HIV prevention programs in high-income countries. PLoS Medicine, 4(9), p.e275. https://doi.org/10.1371/journal.pmed.0040275

UNESCO. 2009. International technical guidance on sexuality education: An evidenceinformed approach for schools, teachers and health educators (Volumes 1-2). Paris: UNESCO.

UNESCO. 2012. Opportunities lost: The impact of grade repetition and early school leaving. Global Education Digest 2012. Paris: UNESCO.

UNESCO. 2013. Ministerial commitment on comprehensive sexuality education and sexual and reproductive health services for adolescents and young people in Eastern and Southern African (ESA). www.youngpeopletoday.org 
UNESCO. 2017. CSE scale-up in practice: Case studies from Eastern and Southern Africa. Paris: UNESCO.

UNESCO. 2018a. International technical guidance on sexuality education: An evidenceinformed approach (Revised Edition). Paris: UNESCO.

UNESCO. 2018b. A civil society perspective: Fulfilling our promise to young people today: Progress review report on the implementation of the Eastern and Southern African ministerial commitment on comprehensive sexuality education and sexual and reproductive health services for adolescents and young people 2015-2017. Paris: UNESCO.

UNESCO. 2018c. Review of the evidence on sexuality education, report to inform the update of the UNESCO International Technical Guidance on Sexuality Education. Developed by Paul Montgomery and Wendy Knerr. Oxford: Centre for Evidence-Based Intervention (CEBI), Department of Social Policy and Intervention, University of Oxford Press.

UNESCO, UNFPA and UNAIDS. 2016. Fulfilling our promise to young people today: 2013-2015 progress review. Durban: UNESCO, UNFPA and UNAIDS.

UNFPA. 2012. Sexuality Education: A ten country review of school curricula in Eastern and Southern Africa. New York, NY: UNFPA.

UNFPA. 2013. Adolescent pregnancy: A review of the evidence. New York: UNFPA.

UNICEF Evaluation Office. 2012. Global evaluation of life skills education programmes. Final Report. New York: UNICEF.

Verma, R., Pulerwitz, J., Mahendra, V.S., Khandekar, S., Singh, A.K., Das, S.S. and Barker, G. 2008. Promoting gender equity as a strategy to reduce HIV risk and genderbased violence among young men in India. Horizons Final Report. Washington, DC: Population Council.

World Bank Group. 2015. Out-of-school youth in sub-Saharan Africa: A policy perspective, Keiko Inoue, Emanuela di Gropello, Yesim Sayin Taylor, and James Gresham, editors. https:/ / elibrary.worldbank.org/doi/10.1596/978-1-4648-0505-9_fm. 